\title{
Increase Hope and Anger Management of Mothers with Children with Cancer through Life Skills Training
}

\author{
Soheyla Siahpoush Koliai ${ }^{1}$, Simindokht Rezakhani ${ }^{2, *}$
}

${ }^{1}$ MA in Counseling, Islamic Azad University, Roudehen, Iran

${ }^{2}$ Assistant Professor, Department of Counseling, Islamic Azad University, Roudehen, Iran

\section{ARTICLE INFO}

\section{Article History}

Received: 6 August 2019

Revised: 21 October 2020

Accepted: 14 November 2020

Available online: February 2021

Article Type

Research Article

Keywords

Life skills; Hope; Anger control

Corresponding Author*

Simindokht Rezakhani received her Ph.D. in Islamic Azad University Sciences and Research Branch of Tehran. She is currently an Assistant Professor in Department of Counseling at Roudehen Branch Islamic Azad University. Her research interest are intervention for individual, family and pair problems.

Correspondence concerning this article should be addressed to Dr Rezakhani, Department of Counseling, Faculty of Education and Counseling, Roudehen Branch, Islamic Azad University. Ayatollah Kameneie Ave, Roudehen. Postal Code 3973188981.

ORCID: 0000-0001-9270-3632

E-mail: rezakhani@riau.ac.ir

doi: http://dx.doi.org/10.29252/bjcp.14.2.83

\section{ABSTRACT}

Cancer is one of chronic diseases. People with cancer need permanent treatment and care and this causes the patient and their families to be in difficult situation. The purpose of this study was to investigate the increase of hope and anger management of mothers with children with cancer through life skills training (interpersonal relationship, problem solving, and anger control).

This research was a quasi-experimental research with pretestposttest and control group. The statistical population of this study was all mothers with children with cancer in MAHAK who were treated in the second half of 1396 and the first half of 1397 (by the end of April) with cancer patients. A total of 36 people who received the lowest score in Schneider Hope Scale (1991) and Spielberger State - Trait Anger Expression Inventory (1999) were voluntarily assigned to the sample group and randomly assigned to two experimental and control groups. life skills (interpersonal relationships, problem solving, anger control) training was taught in 7 sessions of 90 minutes and weekly to the experimental group. After the training, both experimental and control groups were subjected to post-test.

The results of multivariate covariance analysis indicated that interpersonal relationships, problem solving and anger control skills training is effective in increasing hope and anger management of mothers with children with cancer.

Overall, the finding of this research showed as an effective method that learning of above life skills is effective on anger reduce and increase of hope.

Citation: Siahpoush Koliai, S., \& Rezakhani, S. (1399/2021). Increase hope and anger management of mothers with children with cancer through life skills training. Contemporary Psychology, 14(2), 81-88. http://dx.doi.org/ 10.29252/bjcp.14.2.83 


\section{افزايش اميدوارى و مديريت خشم مادران داراى كودكان مبتلا به سرطان \\ از خلال آموزش مهارتهاى زندكى}

سيهيلا سياهيوش كليائى '، سيمين دخت رضاخانى ؟r:

' كارشناس ارشد مشاوره، دانشكاه آزاد اسلامى، رودهن، ايران

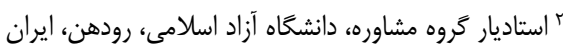

سرطان ازجمله بيمارىهاى مزمن بلشمار مىرود. افراد مبتلا به سرطان به درمان و مراقبت

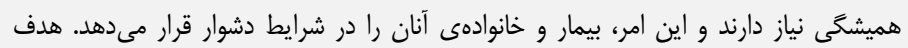

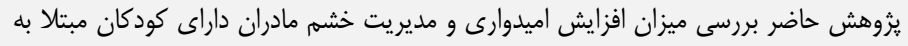

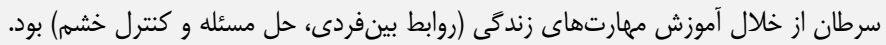

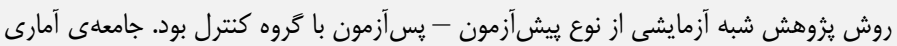

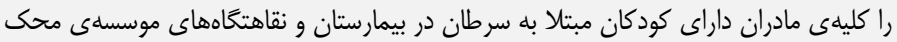

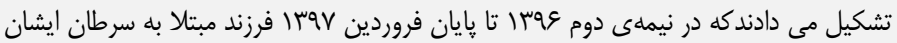
تحت درمان يزشكى قرار داشت. عب نفر كه در يرسشنامهى اميدوارى اشنايدر و همكاران (1991)

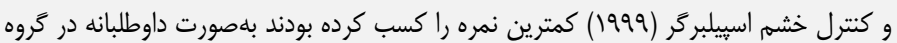

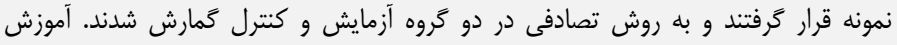

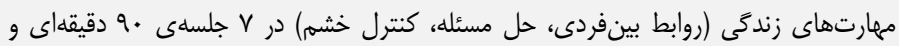

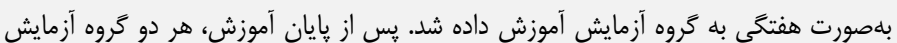
و كنترل مورد يسآزمون قرار كرفتند.

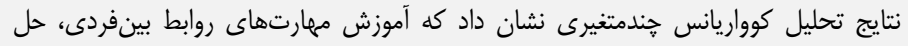

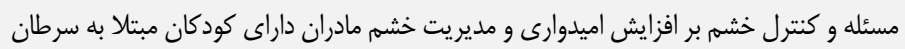
مؤثر است. - است بنابراين آموزش مهارتهاى روابط بينفردى، حل مسئله و كنترل خشم را مىتوان بهاعنوان يكى روش مؤثر جهت كاهش خشم و افزايش اميدوارى به كار گرفت.
دريافت: ها مردادماه هوسار

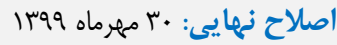

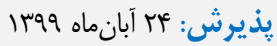

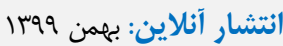

نوع مقاله

مقالهى يزوهشى معاله

كليدوازهها

مهارتهاى زندگَى؛ اميدوارى؛ كنترل خشم

* نويسندهى مسنئول

سيمين دخت رضاخانى درجهى دكترى مشاورهى خود را از دانشعاه آزاد

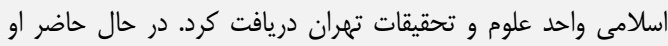

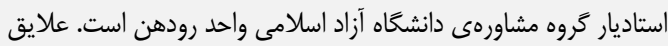

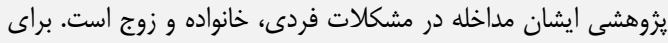

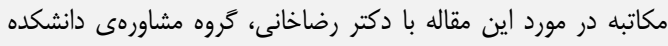

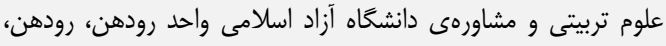

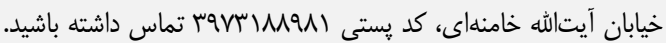
اركيد: 2632-0000-0001-9270

rezakhani@riau.ac.ir : يست الكترونيكى

تلاشهاى درمانى هميشه موفقيتآميز نيست و كودى مبتلا به

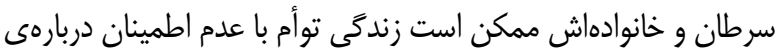

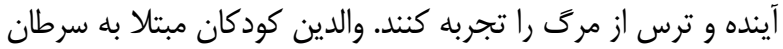

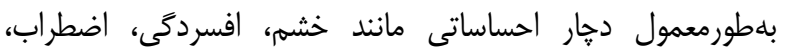
ناميدى و احساس كَاه مىشوند (نعمتى، رسولى، ايلخانى و باغستانى،

در اين راستا، يزوهش ساهلر، دالخين، فييس، فير كلاو، اسكينز

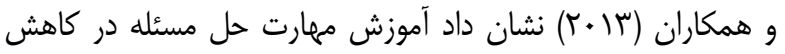

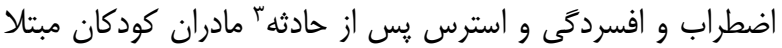
به سرطان مؤثر است. درواقع، دريافت خبر ابتلاى فرزند به بيمارى إنى إنى
سرطان'، بيمارى سلولهاست كه تكثير غيرطبيعى و وان

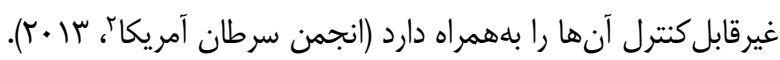

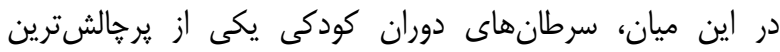

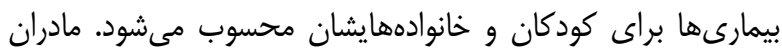

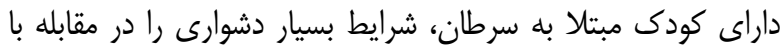
بيمارى فرزندشان تجربه مى كنند. در طى فرايند تشخيص و و درمان اندان

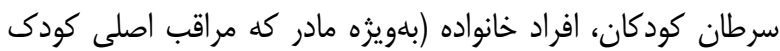

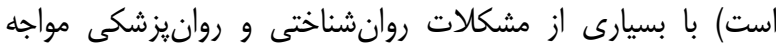

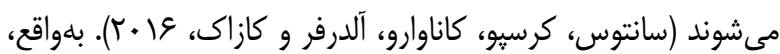


هستند و عملكرد آنان براى بهزيستى كودى و خانواده بسيار مهمه

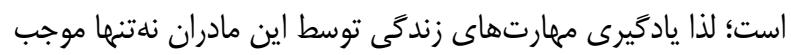

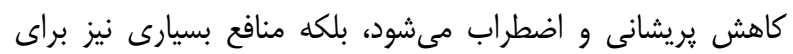

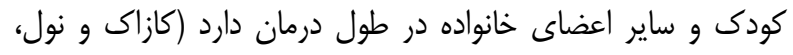

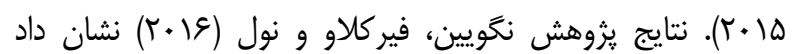

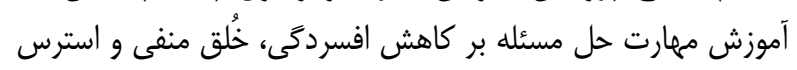

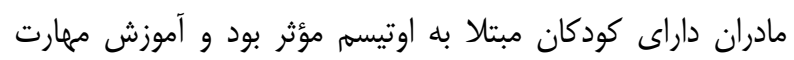

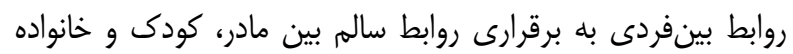

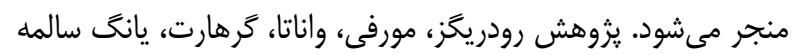

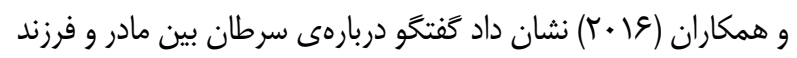

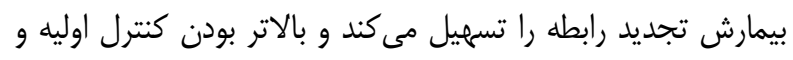

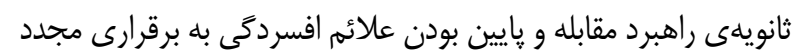
روابط مادر و فرزند منجر مىشود.

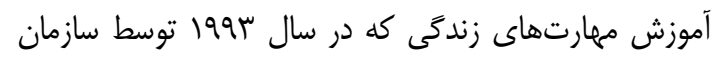

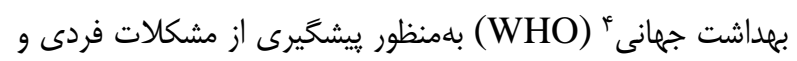

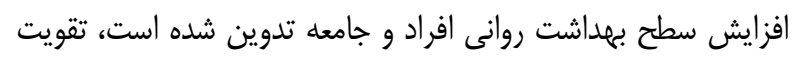

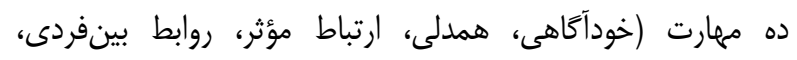
تصميمكيرى، حل مسئله، تفكر خلاق، تفكر انتقادى، تواني، إنائ كنترل

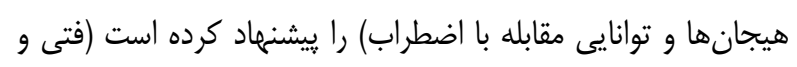

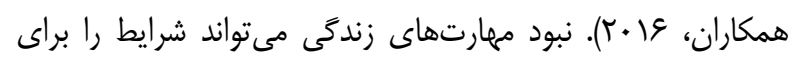

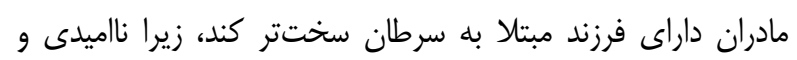

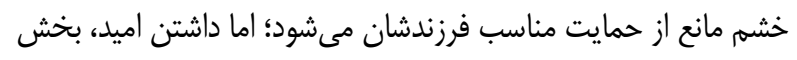

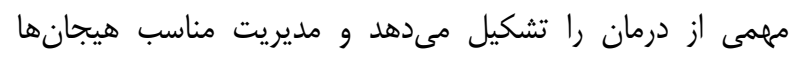

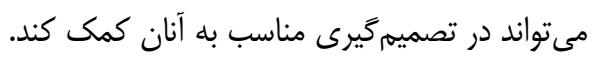

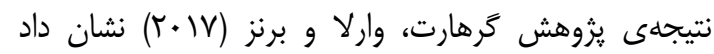

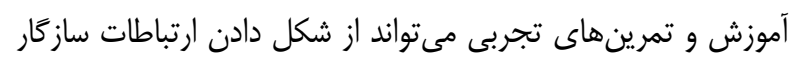

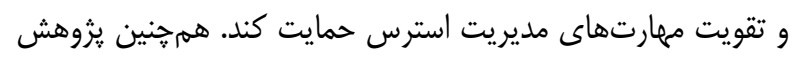

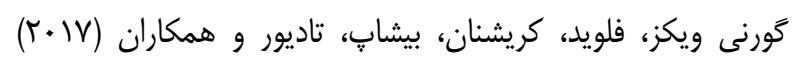

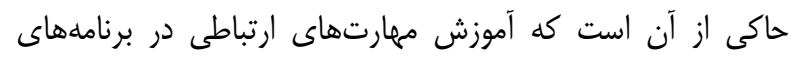

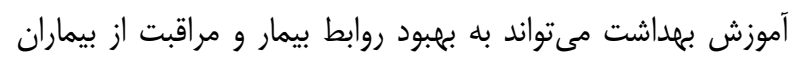

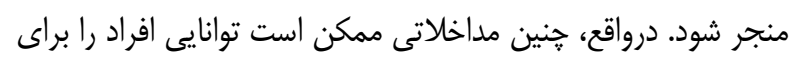

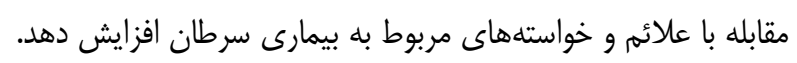

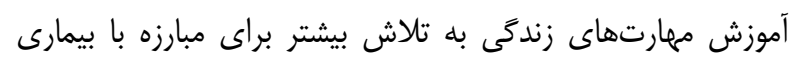

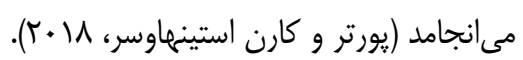

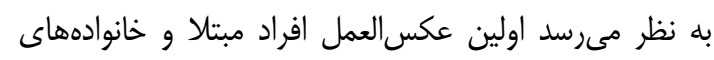

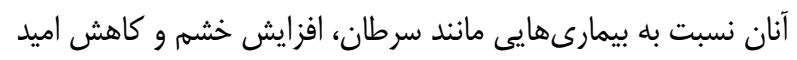

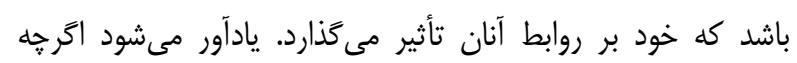

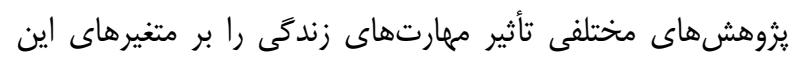

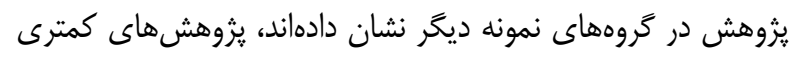

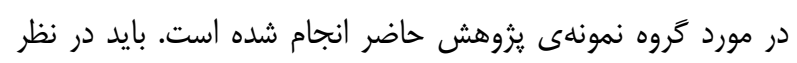

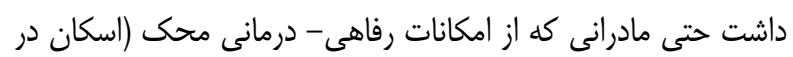

سرطان، رويداد فشارزاى روانى شديدى براى والدين محسوب مىشود.

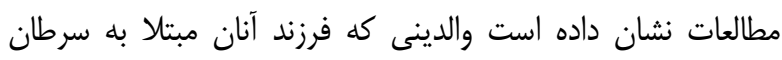

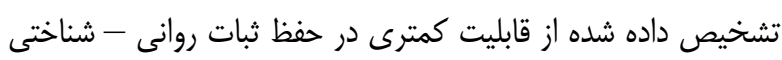

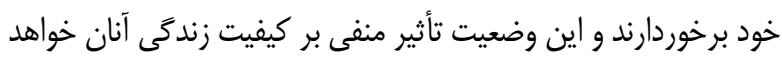
كذاشت (اشنايدر و مانل، 9. (؟).

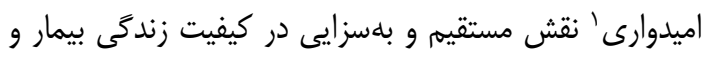

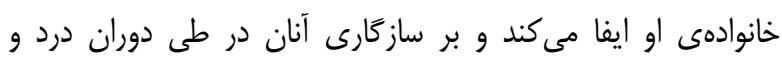

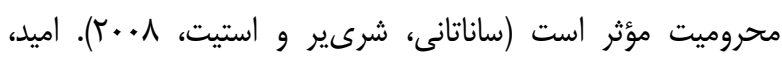

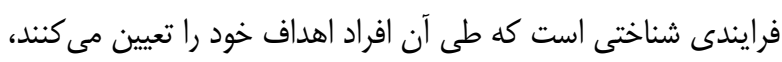

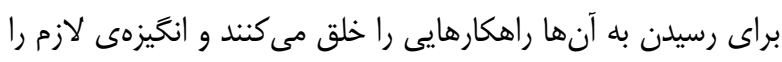

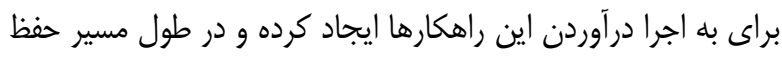

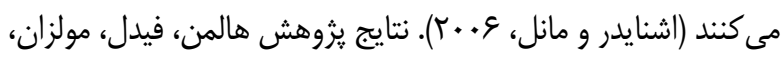

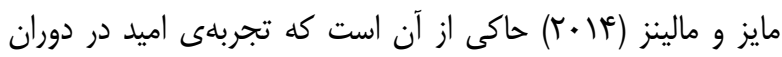

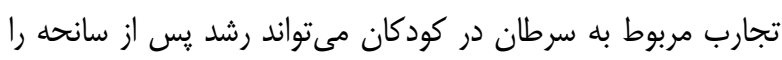

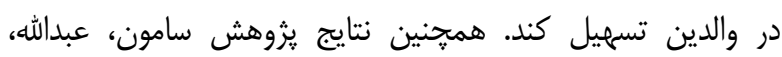

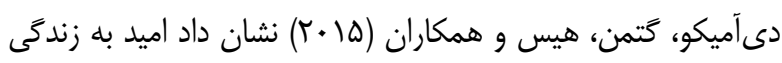
براى كمى به تصميمكيرى هاى درمان مهرم است.

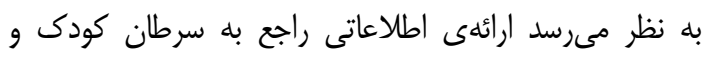

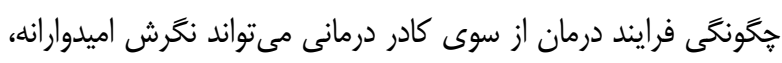

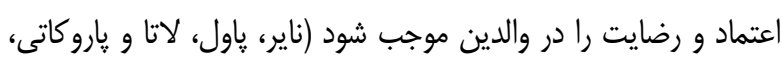

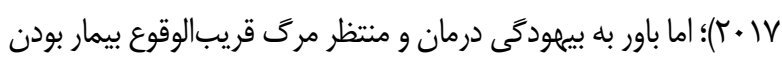

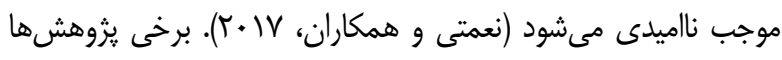

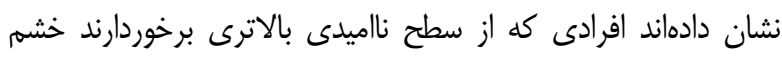

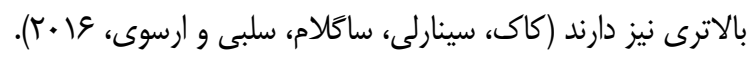

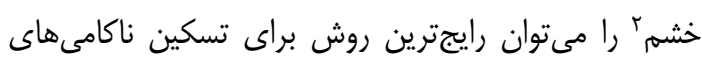

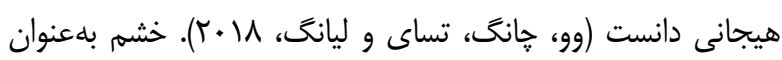

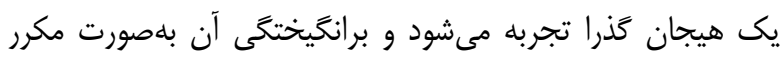

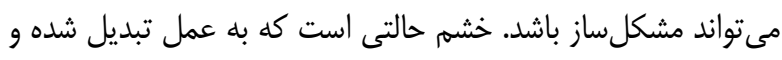

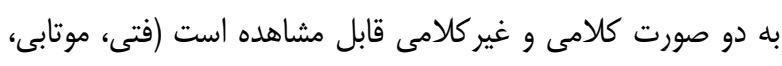

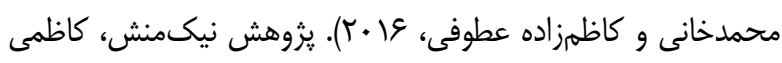

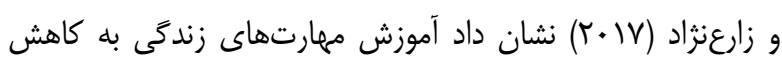

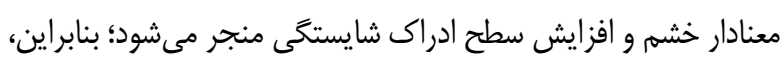

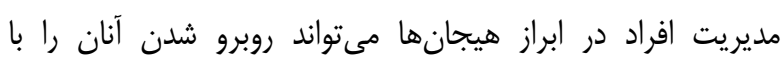

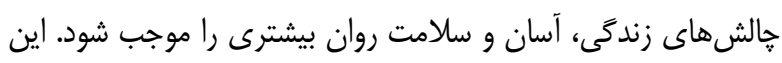

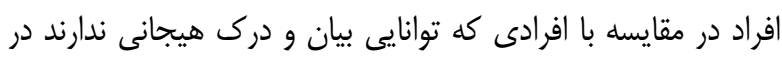

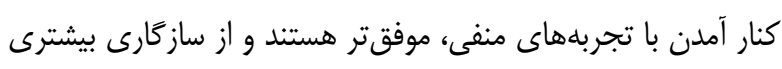

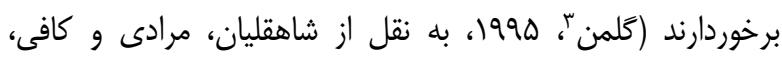

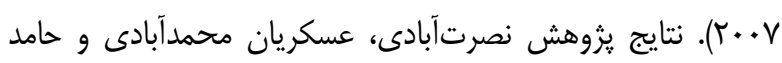

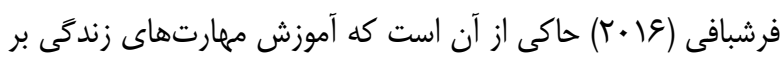

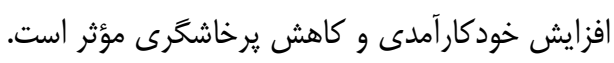

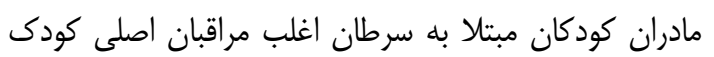


مبتال به سرطان (محك) بود كه در بازمى زمانى نيمهى دوم سال

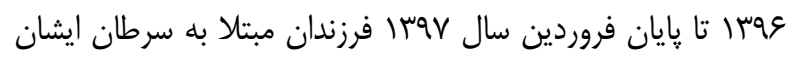

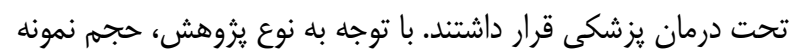

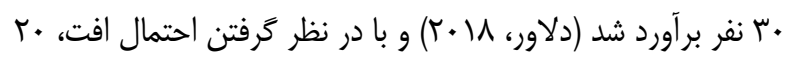

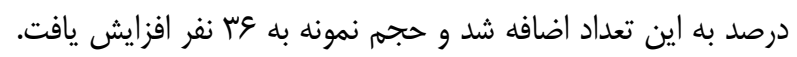

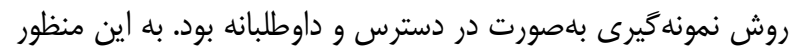

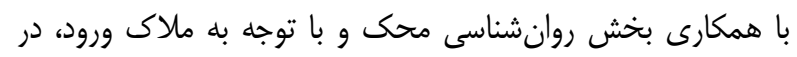

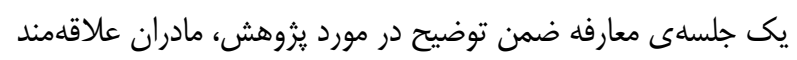

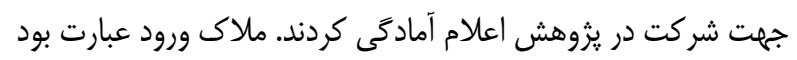

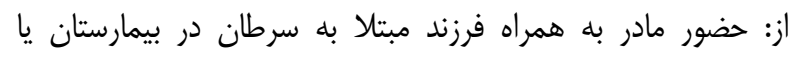

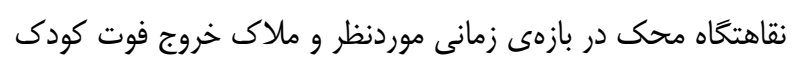
مبتلا به سرطان در نظر كَرفته شد.

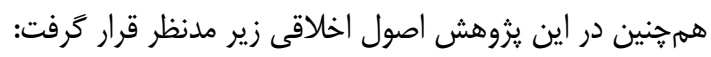

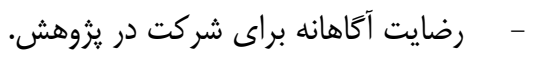

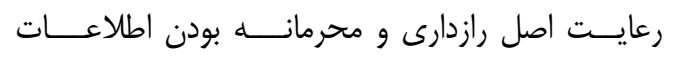

$$
\text { شركت كنندكان. }
$$

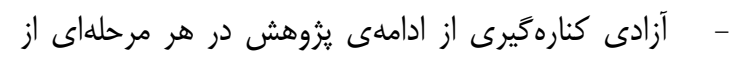

بركزارى جلسات آموزش مهارتهاى ارتباط بينفردى، حل مسئله و كنترل خشم براى تروه كنترل.

مقياس /ميدوارى /شنايدر': اين مقياس توسط اشنايدر (1991)

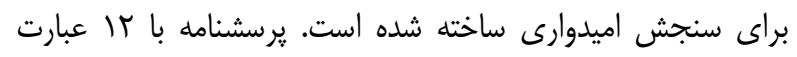

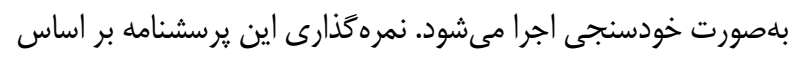

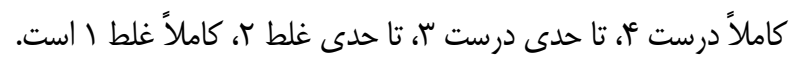

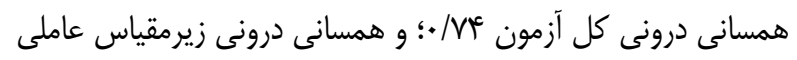
يا

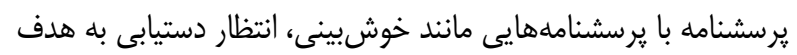

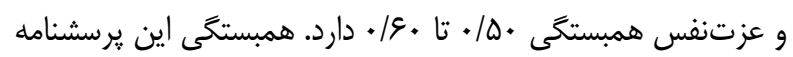

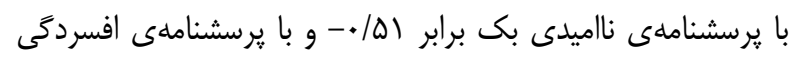

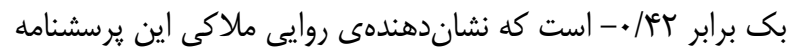

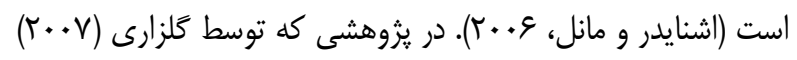

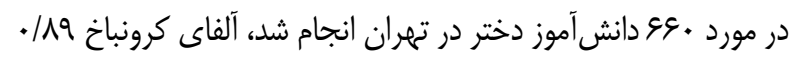

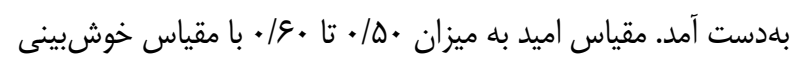

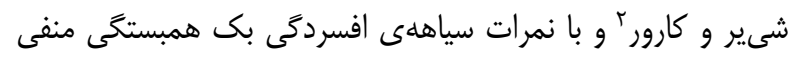

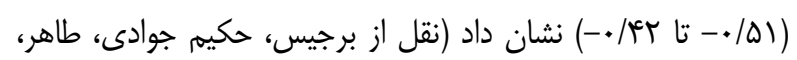

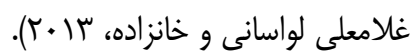

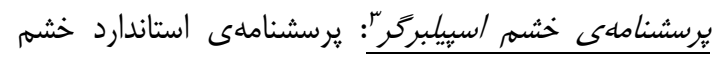

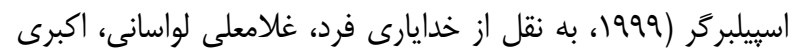

اقامتكاههاى محك، برخوردارى از بهترين امكانات دارويى و درمانى،

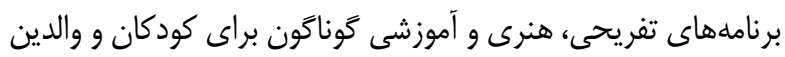

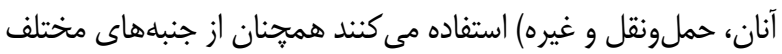

$$
\text { تحت تنش و فشار روانى هستند. }
$$

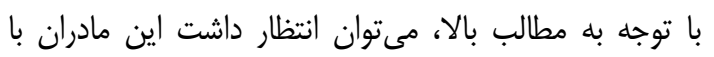

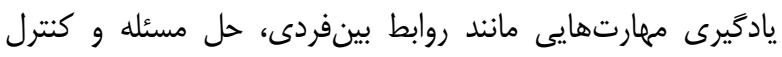

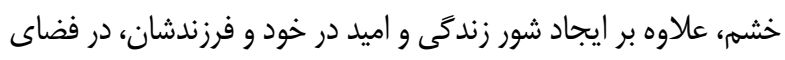

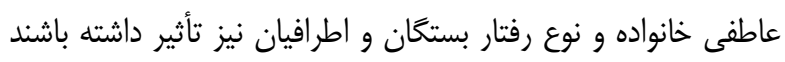

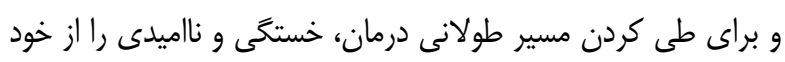

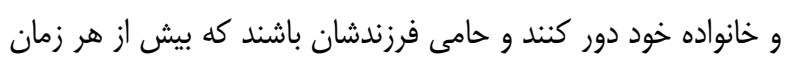
ديخرى به حمايت او نياز دارد.

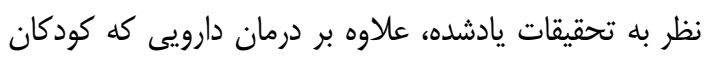

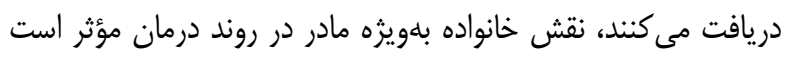

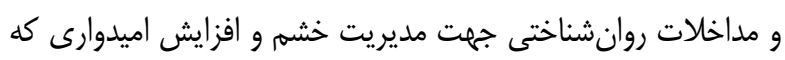

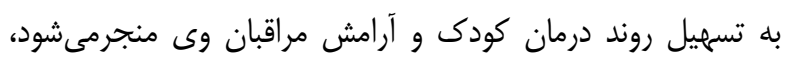

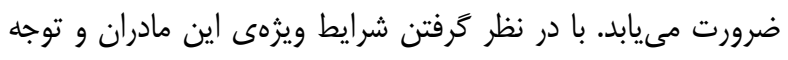

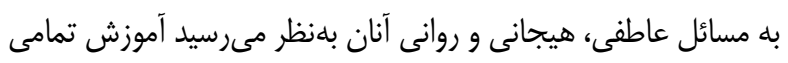

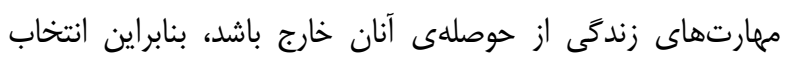

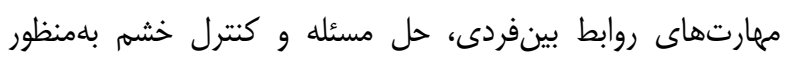

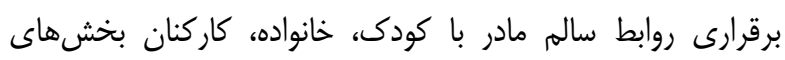

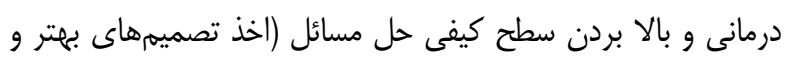

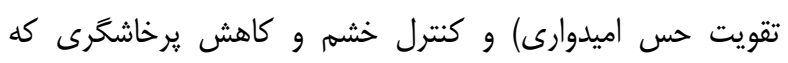

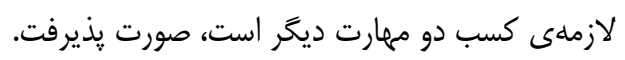

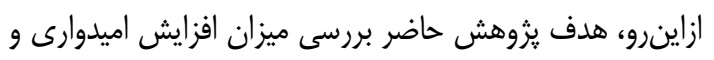

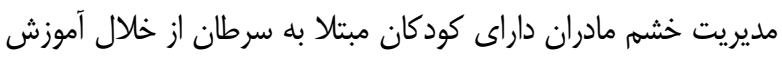
مهارتهاى زندگى (روابط بينفردى، حل مسئله و كنترل خشمه) است.

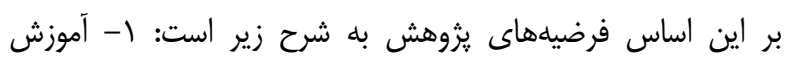

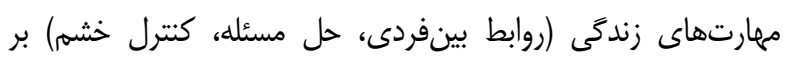

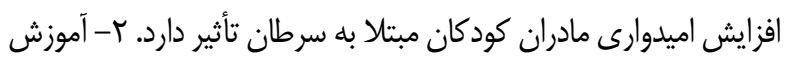

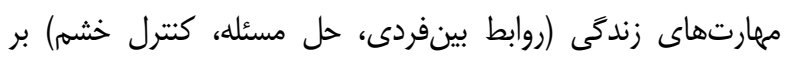
افزايش مديريت خشهم مادران كودكان مبتلا به سرطان لتان تأثير دارد.

\section{روش}

\section{طرح آزمايشى}

اين يزوهش از نوع شبه آزمايشى با طرح ييش آزمون - پِّآزمون

$$
\text { با كروه كنترل است. }
$$

شركت كنندكان

جامعلى آمارى شامل مادران داراى كودكان مبتلا به سرطان

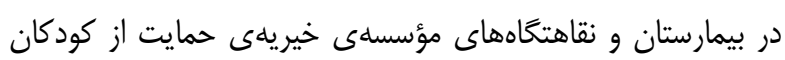


نتايج

براى تجزيهوتحليل دادها از تحليل كوواريانس جندمتنغيرى

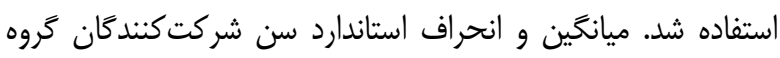

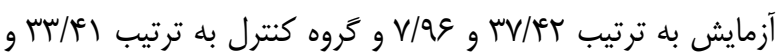

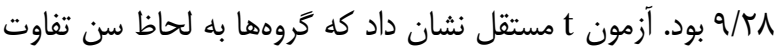

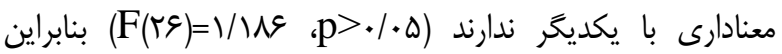
كروهها به لحاظ سن همكن هستند. با توجه به دادههاى جدول r شاخصهاى شائ هاييرو - ويلك

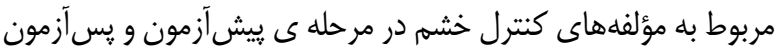

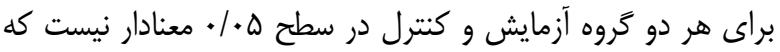

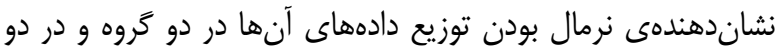

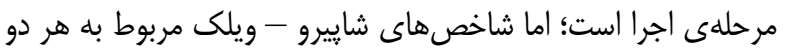

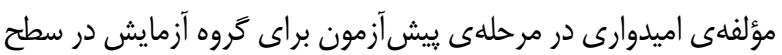

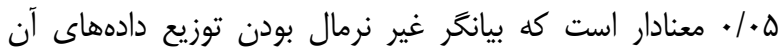

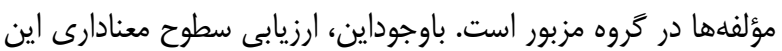

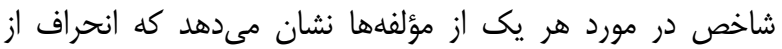

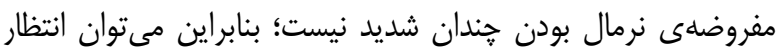

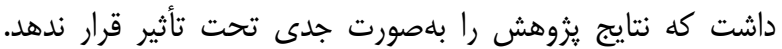

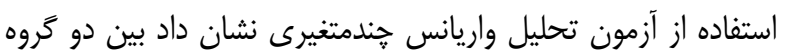

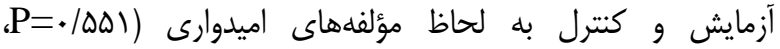

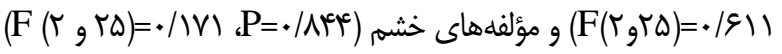
در مرحلهى ييشآزمون تفاوت معنادارى وجود نداردي؛ بنابراين

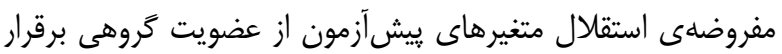

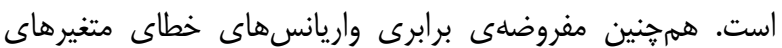

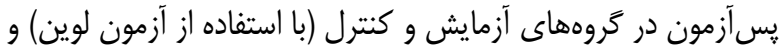

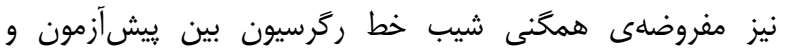

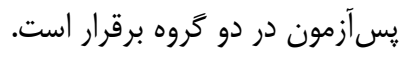

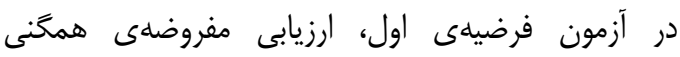

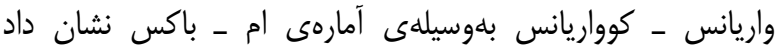

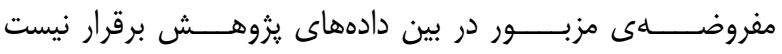

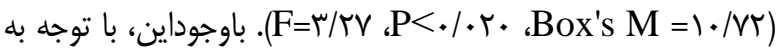
سطح معنادارى بهدستآمده مىتوان كفت انحراف از مفروضه، شديد نيست و مىتوان انتظار داشت كه نتايج تحليل را تحت تأثير قرار ندهان أنداف
زردخانه و لياقت، • (·+) مقياسى مداد كاغذى است كه هV ماده دارد و شامل شش مقياس و ينج خردهمقياس است و مادههاى آن در سله

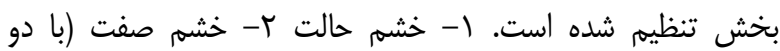

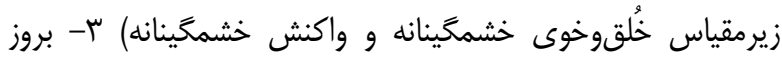
كتترل خشم (با زيرمقياس هاى بروز خشم بيرونى، كنترل خشم درونى

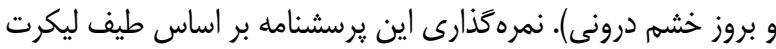

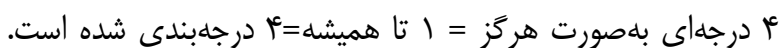

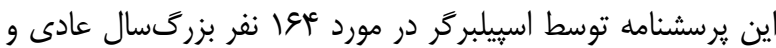
خود TVG

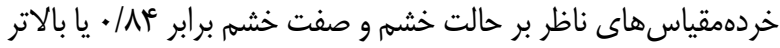
و براى مقياسهاى ناظر بر بيان خشه، كنترل خشمه و شاخص كلى باسلى

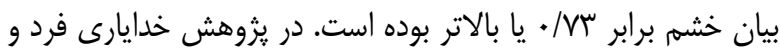

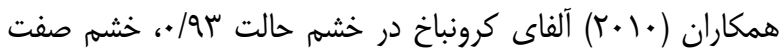

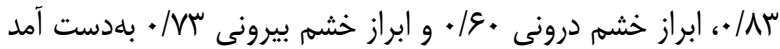

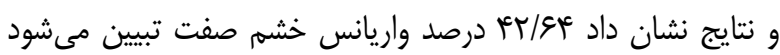
كه نشاندهندهى روايى سازمى يرسشنامه است.

\section{مطالب و محتواى مداخله}

جدول ا خلاصهاى از هدف و محتواى محتواى جلسات آموزشى مهارتهاى روابط بينفردى، حل مسئله و كنترل خشمر را نشان مى دهد.

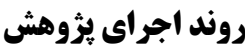

يّ از هماهنكى هاى لازم و اخذ مجوز از مسئولان موسسهى محكى،

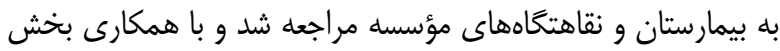
روانشناسى، در مورد مادران حاضر درمحكى (با توجه به ملاكى ورود)

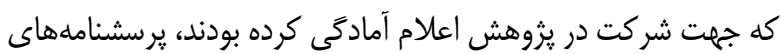

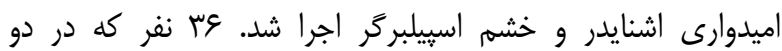

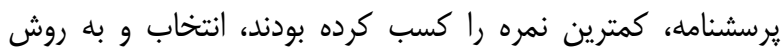

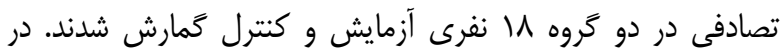

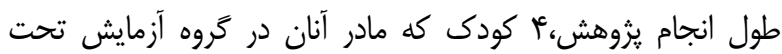

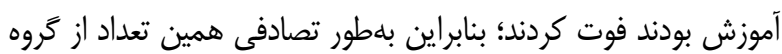

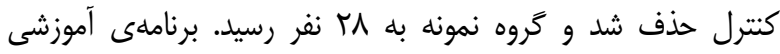

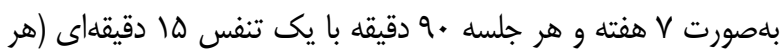

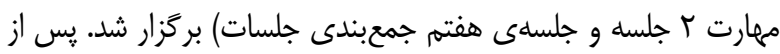

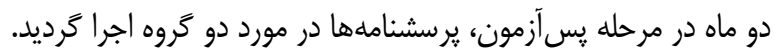
جلدول ا. محتواى جلسات درمانى

\begin{tabular}{|c|c|c|}
\hline محتوا & 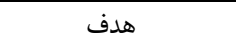 & جلسه \\
\hline توضيح درباره مهارتهاى زندگى و ضرورت يادَّيرى آن. كَتثكو درباره خشم و انواع و عواقب آن & آشنايى & اول \\
\hline آموزش روشهاى كنترل خشم و تمرين اين روشها & 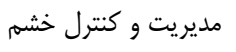 & دوم \\
\hline آموزش مراحل حل مسئله و ترغيب كروه به استفاده از آن در حل مسائل آتى & 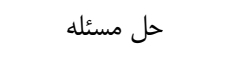 & سوم \\
\hline بررسى تمرينهاى گروه و ارائه راهل هاى بيشتر از طريق بارش فكرى & 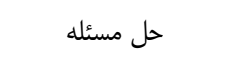 & جهارم \\
\hline بررسى روابط تخريبى و مزاياى روابط بينفردى سالم و ارائه جهارجوب روابط بينفردى & روابط بين فردى & ينجمم \\
\hline تمرين كروهى و تأكيد بر جرئت مندى با رعايت هارجوب روابط بينفردى & روابط بينفردى & ششم \\
\hline مرورى بر آموختهها، كقتتكو و پِاسخ به سؤالات & جمعبندى جلسات & هفتم \\
\hline
\end{tabular}


جدول r. ميانكَين، انحراف استاندارد، شاخص شاييرو- ويلك مؤلفههاى اميدوارى و مؤلفههاى كنترل خشم به تفكيك گروهه و زمان

\begin{tabular}{|c|c|c|c|c|c|}
\hline \multicolumn{2}{|c|}{ شاييرو - ويلك (NS: غير معنادار) } & \multicolumn{2}{|c|}{ ميانكين — انحراف استاندارد } & & \multirow{2}{*}{ كتؤلفهاى خشم اميدوارى و } \\
\hline كروه كنترل & كروه آزمايش & كروه كنترل & كروه آزمايش & & \\
\hline$(\mathrm{NS}) \cdot / 9 \mathrm{~V}^{\mathrm{c}}$ & $(p=\cdot / \cdot+1) \cdot / 1<9$ & $T / \kappa q \pm 11 / T \Lambda$ & $r / r \pm 1 \cdot / V I$ & ييشآزمون & \\
\hline$(\mathrm{NS}) \cdot / 9 \mathrm{rr}$ & (NS) • & $1 / \wedge \varepsilon \pm \| / / \& Y$ & & يس آزمون & \\
\hline$(\mathrm{NS}) \cdot / 94 \wedge$ & $(\mathrm{p}=\cdot / \cdot+\mathrm{\mu r}) \cdot / \mathrm{AV}$. & $r / \Delta \wedge \pm|r / r|$ & $r / \Upsilon \varepsilon \pm 11 / \cdot V$ & ييشآزمون & \\
\hline$(\mathrm{NS}) \cdot / 9 \mathrm{Tr}$ & $(\mathrm{NS}) \cdot|M \Lambda|$ & $1 / \mu \varphi \pm I r / \mu \Delta$ & $T / T V \pm I F / \Gamma \Delta$ & يس آزمون & \\
\hline$(\mathrm{NS}) \cdot / \Lambda \wedge \Delta$ & $(\mathrm{NS}) \cdot / 9 Y \mathrm{~S}$ & $r / r \Lambda \pm I N / \Delta V$ & $F / . . \pm 1 N / 99$ & ي بيشآزمون & \\
\hline$(\mathrm{NS}) \cdot / 9 \Delta \mathrm{V}$ & $(\mathrm{NS}) \cdot / 901$ & $r / F V \pm 19 / 1 T^{c}$ & $r / \Lambda \Delta \pm r r / q r$ & يֶ آزمون & كنترل \\
\hline$(\mathrm{NS}) \cdot / 99 \mathrm{C}^{\circ}$ & $(\mathrm{NS}) \cdot /$ / ৭9 & $r / Q T \pm r \cdot / r \Delta$ & $r / \cdot 1 \pm 19 / \Delta V$ & ييشآزمون & \\
\hline$(\mathrm{NS}) \cdot / 9 \cdot 1$ & $(\mathrm{NS}) \cdot /$ १ q & $r / \cdot t \pm r|r|$ & 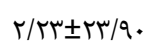 & يسآزمون & تى حشم \\
\hline
\end{tabular}

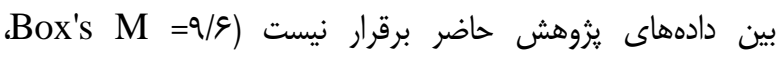

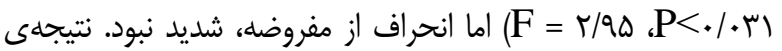

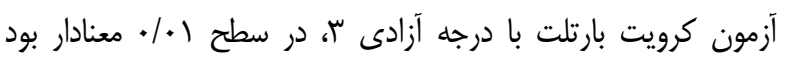
كه نشاندهندهى سطح قابلقبولى از همبستخى بين (X)

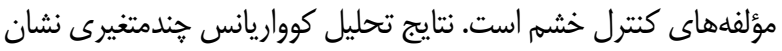

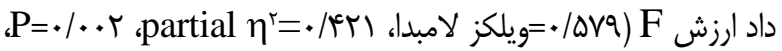

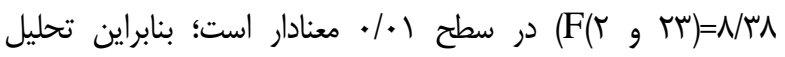
كوواريانس يكراهه انجام شد تا معين شود كداميك از مؤلفههاى كنترل

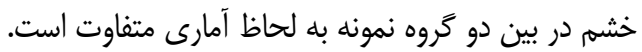
جدول ץ نشان مىدهد كه اجراى متغير مستقل در سطح

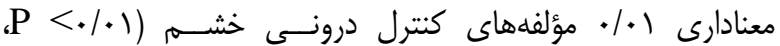
r/ F

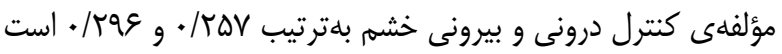

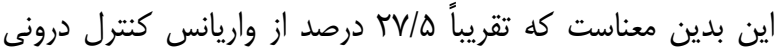

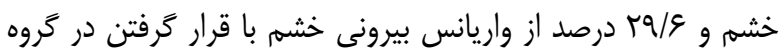

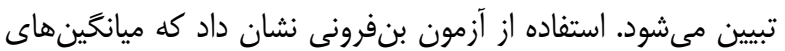

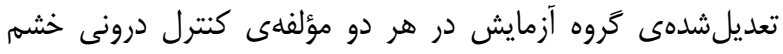

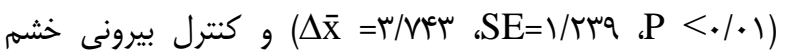
( بلهورت معنادارى بيشتراست؛ بنابراين فرضيهى دوم تأييد مى شود.
نتيجهى آزمون كرويت بارتلت با درجهى آزادى ب در سطح ـ.|.

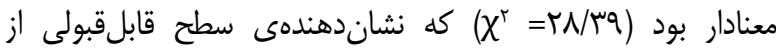

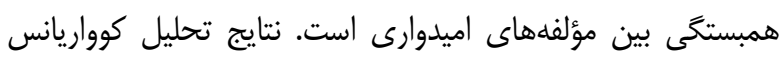

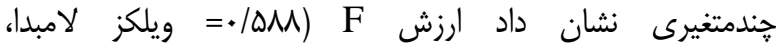

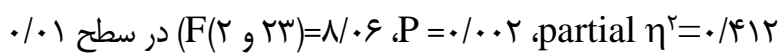
معنادار است. براى تعيين اين كه كداميك از مؤلفههاى اميدوارى در

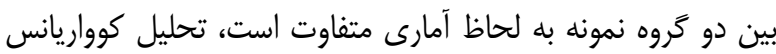
يكراهه انجام شد. بر اساس جدول بّ اجراى متغير مستقل در سطح معنادارى

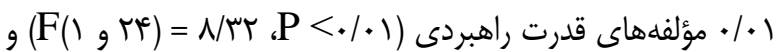

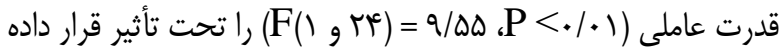

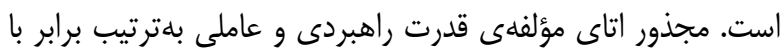

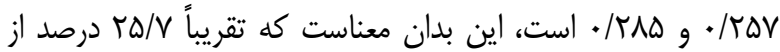

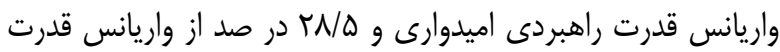

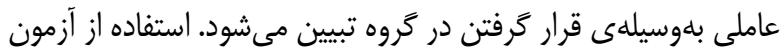

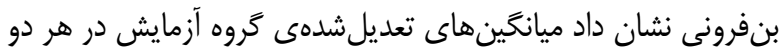

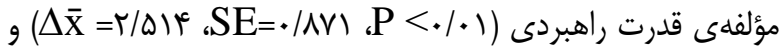
قدرت عاملى (1) معنادارى بيشتراست؛ بنابراين فرضيهى اول تأييد مىشود. در آزمون فرضيلى دوم، ارزيابى مفروضهى همخنى واريانس - كوواريانس

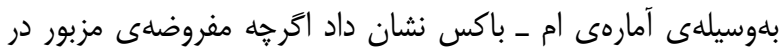

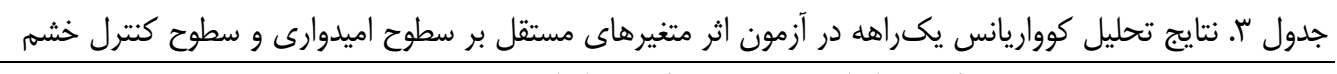

\begin{tabular}{|c|c|c|c|c|c|}
\hline $\operatorname{partial} \eta^{r}$ & سطح معنادارى & $\mathrm{F}$ & $\begin{array}{c}\text { ميانكَين مجذورات } \\
\text { خطات }\end{array}$ & ميانكين مجذورات بين & متغير وابسته \\
\hline - /rar & $\cdot / . .1$ & $N / T r$ & $\Delta / \cdot V$ & $F r / I V$ & قدرت راهبردى \\
\hline - RAD &.$/ . \Delta$ & $q / \Delta \Delta$ & & $r T / S$ & قدرت عاملى \\
\hline . /TVa & .1 .09 & $9 / 14$ & 1.18. & $q \varepsilon / v \checkmark$ & كنترل درونى خشم \\
\hline ع & $.1 .+\varphi^{c}$ & $1.1 . *^{c}$ & s/9 & $99 / 95$ & كنترل بيرونى خشم \\
\hline
\end{tabular}




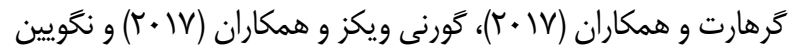

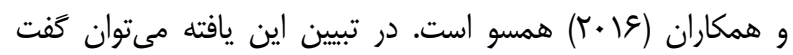

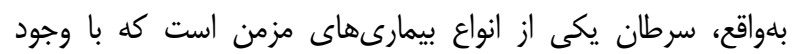

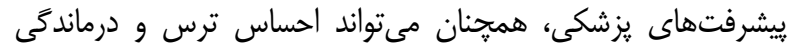

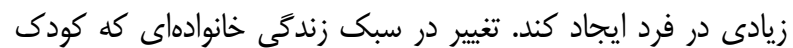

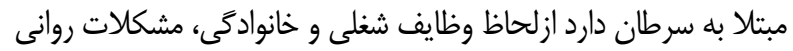

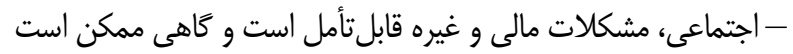

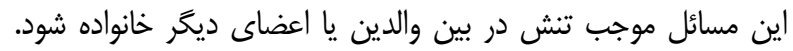
والدين اين كودكان، در معرض مشكلاتى مانند اضطراب، استرس و و ورئر

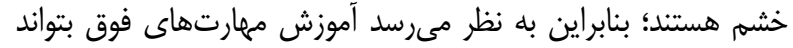

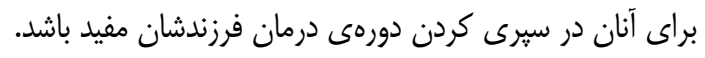

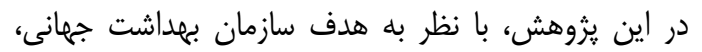

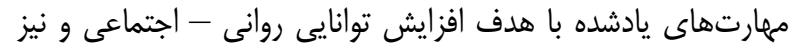

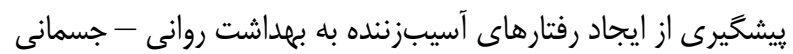

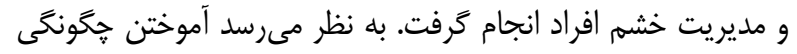

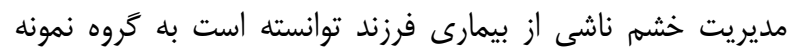

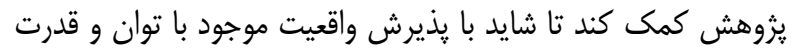

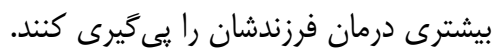

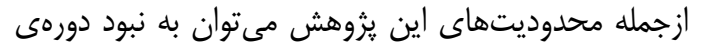

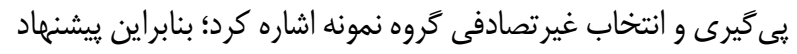

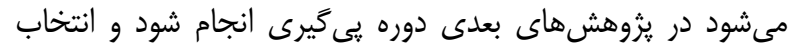

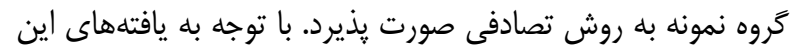

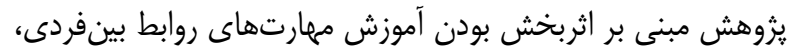

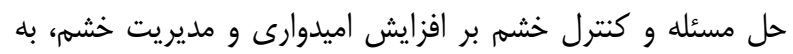

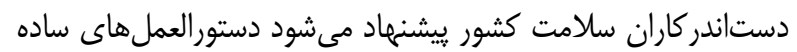

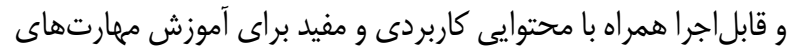

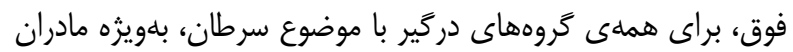

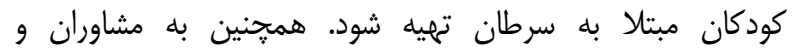

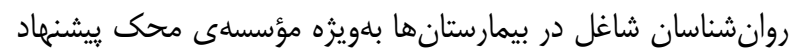
مىشود با بررسى ميزان خشم و اميدوارى والدين كودكان مبتلان به به بهان

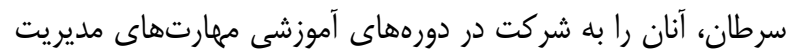

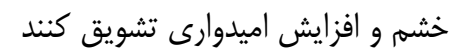

\section{بحث و نتيجه تيرى}

يافتههاى يزوهش نشان داد آموزش مهارتهاى روابط

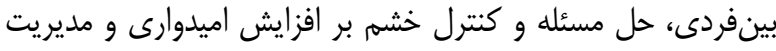

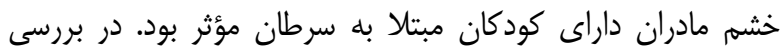

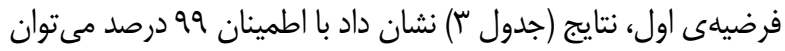

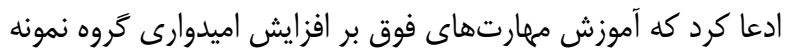

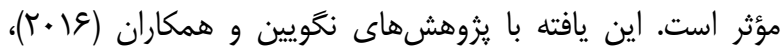

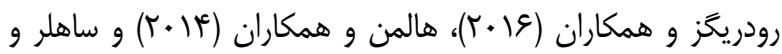
همكاران (T/ + (T) همسو است. در تبيين اين يافته مىتوان به ماهيت دو متغير (مهارتهاى

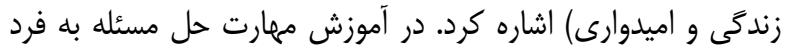

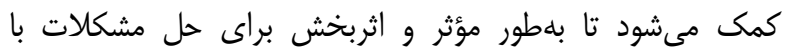
رويكردى منظه به تالشها بيردازد؛ بنابراين فرد مى آموزد تا برخورد

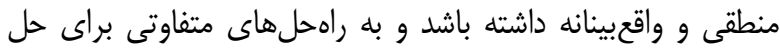
مشكل فكر كند. بهنظر مىرسد وقتى هدف، حل مشكل باشده حركت بلهسوى هدف، احساس اميدوارى را برمىانخيزد. از سوى ديخر، به به نظر مىرسد مادرانى كه كودى مبتلا به سرطان دارند هماندا سائد ساير مادران

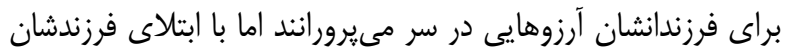

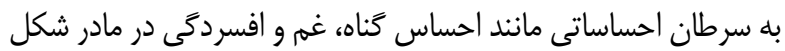

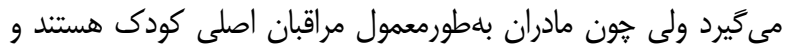

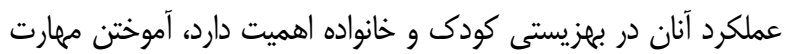

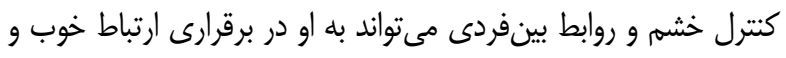

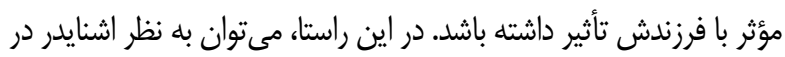

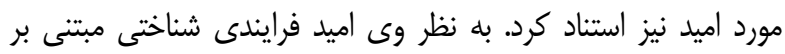
احساس موفقيت ناشى از منابع كَوناكون و مسيرهاست (اشنايدر و مانل،

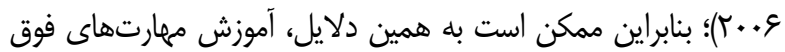

به مادران توانسته باشد به افزايش اميدوارى منجر شود. در بررسى فرضيهى دوم، نتايج (جدول ऍّ) نشان داد آموزش مهارتهاى روابط بينفردى، حل مسئله و كنترل خشم بر افز افز ايش

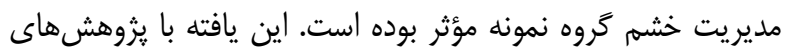

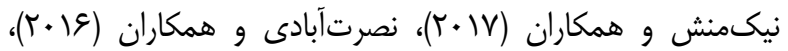

قدر دانى: بر خود لازم مى دانيم از مادران شركت كننده و مسئولان مؤسسهى خيريهى محك كه يزوهشكر را در انجام اين يثوهش يارى كردند صميمانه سياسكزارى كنيه.

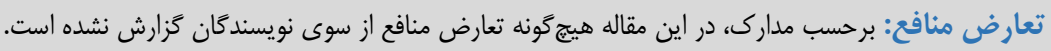

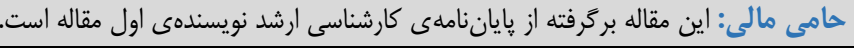

\section{Reference}

Berjis, M., HakimJavadi, M., Taher, M., Gholamali Lavasani, M., \& HosseinKhanzadeh, A. A. (2013). A comparison of the amount of worry, hope and meaning of life in the mothers of deaf children, children with autism and children with learning disability. Journal of Learning Disabilities, 3(1), 148-155. [Persian, 1392]

Cancer American Society. (2013). Cancerinchildren. Http://www.cancer.org/acs/groups/cid/documents
/webcontent/002287-pdf.(Retrieved 2020/3/5).

Delavar, A. (2018). Research Methodology in Psychology and Educational Sciences .Tehran: Virayesh. [Persian, 1397].

Fata, L., Motabi, F., Mohammad khani, Sh., \& Kazemzadeh Atoufi, M. (2016). Life skills training (especially for adults) .Tehran: minkhoshk. [Persian, 1395]. 
Gerhart, J. I., Varela, V. S., \& Burns, J. W. (2017).Brief training on patient anger increases oncology providers' self- efficacy in communicating with angry patients. Journal of Pain and Symptom Management, 54(3), 355-360. [DOI : 10. 1016 / j. jpainsymman.2017.07.039] [PMid:28760523]

Gorniewicz, J., Floyd, M., Krishnan, K., Bishop, T. W., Tudiver, F., \& Lang, F. (2017). Breaking bad news to patients with cancer: A randomized control trial of a brief communication skills training module incorporating the stories and preferences of actual patients. Patient Education and Counseling, 100 (4), 655-666. [DOI : 10 . 1016/ j.pec.2016.11.008] [PMid:27876220 PMCid:PMC5407084]

Hullmann, S. E., Fedele, D. A., Molzon, E. S., Mayes, S., \& Mullins, L. L. (2014). Posttraumatic growth and hope in parents of children with cancer. Journal of Psychosocial Oncology, 32 (6), 696707. [DOI : 10 . $1080 / 07347332$. 2014 . 955241] [PMid:25158296 PMCid:PMC4224605]

Kazak, A. E., \& Noll, R.B. (2015). The integration of psychology in pediatric oncology research and practice collaboration to improve care and outcomes for children and families. American Psychology, 70(2), 146-158. [DOI:10.1037/a0035 695] [PMid:25730721]

Khodayarifard, M., Gholamali Lavasani, M., Akbari Zardkhaneh, S., \& Liaghat, S. (2010). Psychometric properties Spielberger's state - trait Anger Expression Inventory- 2 (among of Iranian students).Journal of Rehabilitation, 11(1), 47-56. [Persian, 1389].

Koc, Z., Cinarli, T., Saglam, Z., Celebi, P., \& Ersoy, B. (2016). Determination of the association between continuous anger, anger expression and hopehopelessness levels in patients with lung cancer. Journal of Thoracic Oncology, 11(4), Supplement Pages S68-S78. [DOI:10.1016/S1556-0864(16) 30162-9]

Nair, M., Paul, L.T., \& Parukkutty. K. (2017).Parents' knowledge and attitude regarding their child's cancer and effectiveness of initial disease counseling in pediatric oncology patients .Indian Journal of Palliative Care, 23(4), 393-398. [DOI: 10.4103/IJPC.IJPC_83_17] [PMid: 29123344 PMCid: PMC5661340]

Neguyen, C., Fairclough, D. L., \& Noll, R. B. (2016). Problem- solving skill training for mothers of children recently diagnosed with autism spectrum disorder: A pilot feasibility study. Autism, 20 (1), 55- 64. [DOI:10.1177/1362361314567134] [PMid: 25896269]

Nemati, S., Rassouli, M., Ilkhani, M., \& Baghestani, A. R. (2017). The spiritual challenge faced by family caregivers of patiants with cancer. A qualitative study. Holistic Nursing Practice, 31(2), 110-117. [DOI:10.1097/HNP.0000000000000198] [PMid: 28181976]

Nikmanesh, Z., Kazemi, Y., \& Zarenezhad Z. (2017). The impact of life skills training on competency perception and anger control in students. Educational Psychology Studies, 14(27), 221-243. [Persian, 1396]

Nosratabadi, M., Askarian Mohammadabad, N., \& hamedfarshbafi, S. (2016). The effect of life skills training on self-efficacy and anger control of Kerman parents. The Second National Conference on sustainable lifestyle and family, Tehran, Islamic Azad University, Science and Research Branch of Tehran [Persian, 1395].

Porter, L. S., \& Karen Steinhauser, L. F. (2018). Themes Addressed by Couples with Advanced Cancer during a Communication Skills Training Intervention. Journal of Pain and Symptom Management, 56(2), 252-258. [DOI:10.1016/j.jpainsymman.2018.04. 004] [PMid:29704618 PMCid: PMC6082423]

Rodriguez, E. M., Murphy, L., Vannatta, K., Gerhardt, C. A., Youg-saleme, T., Saylor, M., Bemis, H., Desjardins, L., Dunn, M. J., \& Compas, B. (2016). Maternal coping and depressive symptoms as predictors of mother- child communication about a child's cancer. Journal of Pediatric Psychology, 41(3), 329-339. [DOI:10.1093/jpepsy/jsv106] [PMid:26609183 PMCid:PMC5013837]

Sahler, O. J. Z., Dolgin, M. J., Phipps, S., Fairclough, D. L., Askins, M. A., katz, E. R., Noll, R. B., \& Butler, R.W. (2013). Specificity of Problem- solving skills training in mothers of children newly diagnosed with cancer: Results of a multisite randomized clinical trial. Journal of Clinical Oncology, 31(10), 1329-1335. [DOI:10.1200/JCO.2011.39.1870] [PMid:23358975 PMCid: PMC3607672]

Sammon, J. D., Abdollah, F., D’Amico, A., Gettman, M., Haese, A., Suardi, N., Vickers, A., \& Trinh, Q. D. (2015). Predicting life expectancy in men diagnosed with Prostate cancer. European Urology, 68(5), 756-765. [DOI:10.1016/j.eururo.2015.03.020] [PMid:25819724 PMCid: PMC4583348]

Sanatani, M., Schreier, G., \& Stitt, L. (2008). Level and direction of hope in cancer patient: An exploratory longitudinal study. Supportive Care in Cancer, 16(5), 493-499. [DOI:10.1007/s00520-007-03366] [PMid:17891421]

Santos, S., Crespo, C., Canvarro, M. C., Alderfer, M. A, \& Kazak, A. E. (2016). Family rituals financial burden and mother's adjustment in pediatric cancer. Journal of Family Psychology, 30(8), 1008-1013. [DOI:10.1037/fam0000246] [PMid: 27617476]

Shahgholian, M., Moradi, A., \& Kafi, S. M. (2007). Relationship of Alexithymia with emotional expression styles and general health in Students College. Iranian Journal of Psychiatry \& Clinical Psychology, 13(3), 238-248. [Persian, 1386].

Schneider, M. A., \& Mansell, R. C. (2006). Beacon in the storm: an exploration of the spirituality and faith of parents whose children have cancer. Journal of Issues in comprehensive pediatric Nursing, 29(1), 3-24. [DOI:10.1080/0146086050 0523731] [PMid:16537278]

Wu. W. W. Chang. J. T., Tsai. S. Y., \& Liang. S. Y. (2018). Assessing self-concept as mediator between anger and resilience in adolescents with cancer in Taiwan .Cancer Nursing, 41(3), 210-217. [DOI:10.1097/NCC.0000000000000512] [PMid:28537955] 